\title{
Yönetim Kurulu Kalitesinin Firma Performansı Üzerindeki Etkisi: BİST-100 Firmaları Üzerine Bir Araştırma*
}

\author{
Erol TEKİN**
}

\author{
Selim Koray DEMİREL***
}

\begin{abstract}
$\ddot{O} Z$
Firmalarda yönetim kurullarl, en üst kademe organ olarak önemli roller üstlenmektedirler. Yönetim kurulu kalitesinin de firma performansinın üzerinde önemli bir etkiye sahip olduğu düşünülmektedir. Çalışmada, yönetim kurulu kalitesi ve firma performansı arasındaki ilişskinin gelişmekte olan bir ülke olarak Türkiye bağlamında ele alınması amaçlanmıştır. Bu amaçla, 2015 yllında Türkiye'de faaliyet gösteren ve Borsa İstanbul 100 endeksinde (BIST 100) yer alan sanayi firmalar 2009-2014 dönemi verileri kullanılarak incelenmiştir. Yönetim kurulu kalitesi hesaplanırken Bin-Sariman vd., (2015) tarafindan oluşturulan Yönetim Kurulu Kalite Endeksi'nden (BDQ) yararlanılmıştır. Gelişstirilen hipotezler panel veri analizi ile test edilmiştir. Sonuçlar, Türkiye'de yönetim kurulu kalitesinin muhasebe tabanl firma performansinı pozitif ve anlaml bir şekilde etkilediğini göstermektedir. Bununla birlikte, yönetim kurulu kalitesinin piyasa esasl performans üzerinde bir etkisinin olmadĭ̆ tespit edilmiştir. Çalışma, yönetim kurulu yapısının firma performansı üzerindeki etkisini incelerken toplulaştırılmış bir endeks kullanılması nedeniyle literatüre katkıda bulunmaktadır.
\end{abstract}

Anahtar Kelimeler: Yönetim Kurulu Kalitesi, CEO İkiliği, Kadın Üye, Firma Performansı JEL Siniflandirması: G30, G34, L25

\section{The Effect of Board of Directors' Quality on Firm Performance: A Study on BIST-100 Companies}

\begin{abstract}
Board of directors in the companies are playing important role as the highest authority. It is thought that board of directors' quality also has an important effect on the firm performance. In this study, the aim is to investigate the relationship between the quality of the board of directors and the performance of the firms in Turkey which is a developing country. Within the scope of this aim, the firms operating in 2015 and taking place in Istanbul Market Index 100 (BIST 100) are analyzed by using the data between 2009 and 2014. BDQ Index by Bin-Sariman et all. (2015) is imposed when calculating the quality of board of directors. The developed hypotheses are tested with the method of panel data analysis. The results show that the quality of Board of Directors affects accounting-based firm performance in a positive and meaningful way in Turkey. However, it was also determined that the quality of board of directors has no effect on market-based performance. The study, owing to using aggregated index when examining the structure of the Board of Directors on the performance of firm, makes contribute to the literature.
\end{abstract}

\footnotetext{
Bu çalışma,19-22 Mayıs 2016 tarihleri arasında Bosna Hersek’te düzenlenen II. Sarajevo International Conference of Social Sciences'ta sunulan aynı adlı bildirinin geliştirilmiş ve gözden geçirilmiş halidir.

** Yrd. Doç. Dr. Kastamonu Üniversitesi İktisadi ve İdari Bilimler Fakültesi, Uluslararası Ticaret ve Lojistik Bölümü, erolktu@gmail.com

**** Arş. Gör. Karadeniz Teknik Üniversitesi İktisadi ve İdari Bilimler Fakültesi, İktisat Bölümü selimkoraydemirel@gmail.com
} 
Performance

Key Words: Board of Director's Quality, CEO Duality, Female Members, Firm

JEL Classification: G30, G34, L25

\section{GíRIŞ}

Yönetim kurulları firmalarda pay sahipleri adına firmayı yönetmek için görevlendirilen organdır. Yani yönetim kurulları, bir vekil olarak onları seçen ve görevlendiren pay sahiplerine karşı sorumlu bir biçimde firmayı yönetirler (Ülgen \& Mirze, 2013, s. 468). Bu kapsamda yönetim kurullarının üzerinde bir takım önemli görev ve sorumluluklar bulunmaktadır. Öyle ki, yönetim kurullarının temel politikaları oluşturma ve yürütme, dış çevreyle iletişimi kurma ve en önemlisi firmanın yaşamını sürdürebilmesi için gözetimi gibi görevleri söz konusudur (Gökçen vd., 2012, s. 78). Bu önemli görevleri dikkate alındığında yönetim kurulları firmanın başarısını doğrudan etkileyen bir faktördür. $\mathrm{Bu}$ noktada yönetim kurulu yapısının firmanın performansını nasıl etkileyeceği sorusu akla gelmektedir (O’Connell \& Cramer, 2010, s. 387).

$\mathrm{Bu}$ bağlamda son zamanlarda, kurumsal yönetim literatüründe yönetim kurullarının firma başarısına etkisini inceleyen çalışmaların sayısı artmaya başlamıştır (Hermalin \& Weisbach, 1991; Arosa vd., 2010; Bozec, 2005; Carter vd., 2003; Elsayed, 2011; O'Connell \& Cramer, 2010; Priya \& Nimalthasan, 2013; Taghizadeh \& Saremi, 2013; Ujunwa, 2012; Abdullah, 2004; Tian \& Lau, 2001; Shakir, 2008; Staikouras vd., 2007; Wan \& Ong, 2005; Perry \& Shivdasani, 2005). Bu çalışmalara bakıldığında yönetim kurulu büyüklüğü, bağımsız üye oranı, CEO ve yönetim kurulu başkanının aynı kişi olması, kadın üye oranı, yabancı üye oranı, yönetim kurulu üyelerinin çeşitliliği gibi konuların ayrı ayrı ele alındığ görülmektedir. Bu çalışmada ise Bin-Sariman vd., (2015) tarafından geliştirilen yönetim kurulu kalitesi endeksi Türkiye'ye uyarlanarak kullanılmıştır. Bu kapsamda çalışmada yönetim kurulu kalitesinin firmanın finansal performansı üzerindeki etkisi ortaya konulmaya çalışılmıştır. Bununla birlikte son zamanlarda literatürde sıklıkla tartışılan CEO ikiliği ve yönetim kurulu kadın üye oranının da firma performansı üzerindeki etkileri incelenmiştir. Türkiye bağlamında yönetim kurulu kalitesini gösteren toplulaştırılmış bir endeksin kullanılmasının literatüre bir katkı sağlayacağı düşünülmektedir.

$\mathrm{Bu}$ çerçevede izleyen bölümde, konuyla ilgili literatür taraması gerçekleştirilmiştir. Ardından, çalışmada kullanılan değişkenler tanıtılarak oluşturulan hipotez ve modeller sunulmuştur. Sonrasında ise araştırma bulgularının sunulduğu bölümü takiben, çalışmanın sonuçları ve genel bir değerlendirmesi yapılarak çalışma tamamlanmıştır.

\section{LITERATÜR TARAMASI}

\section{A. Yönetim Kurulu Kalitesi}

Literatür incelendiğinde, yönetim kurulu karakteristiğinin firma performansı üzerindeki etkilerinin genellikle yönetim kurulu büyüklüğü, CEO ikiliği, yönetim kurulundaki bağımsız üye sayısı, yönetim kurulundaki kadın üye oranı gibi değişkenler açısından incelendiği görülmektedir. 
Söz konusu değişkenlerden yönetim kurulu büyüklüğü ile firma performansı arasındaki ilişki, ele alınan temel konulardan bir tanesidir. Yapılan çalışmalar incelendiğinde ideal yönetim kurulu sayısının ne kadar olması gerektiği noktasında genel bir görüş yoktur. Ancak yönetim kurulu büyüklügünün artmasının firmaların performansı üzerinde olumsuz bir etkisi olduğunu ortaya koyan çok sayıda çalışma mevcuttur (Bonn vd., 2004; Yermack, 1996; Conyon \& Peck, 1998; Mak \& Yuanto, 2001; Bennedsen vd., 2008; Cheng vd., 2008). Bununla birlikte, az sayıda olmakla birlikte yönetim kurulu büyülügünün firma performansını olumlu yönde etkilediğini belirten çalışmalar da vardır (Aygün vd., 2011; Larmou \& Vafeas, 2009; Bozec, 2005; Kyereboah-Coleman \& Biepke, 2006). Bu çerçevede literatürde hâkim olan görüş yönetim kurulu üye sayısının fazla olmasının vekalet problemlerini artıracağı ve firmayı olumsuz etkileyeceği yönündedir. Çalışmada da yönetim kurulu büyüklüğü literatürle tutarlı bir şekilde endekse dâhil edilmiştir.

Bağımsız yönetim kurulu üyeliğinin firma başarısına etkisi literatürde araştırılan diğer önemli konulardan bir tanesidir. Hussain \& Mallin (2002)'e göre, yönetim kurulu içerisinde bağımsız üyelerin varlığı firmaya farklı bir bakış açısı katmakta ve gelişimine katkı sağlamaktadır. Bununla birlikte Selekler-Gökşen \& Karataş (2008, s. 136)'a göre ise, Türkiye gibi aile firmalarının sayısının fazla olduğu gelişmekte olan ülkelerde, aile üyeleri bağımsız yöneticilere kıyasla firma için daha olumlu potansiyele sahiptir. $\mathrm{Bu}$ bağlamda yönetim kurulu bağımsızlığının firma performansı üzerine etkisine ilişkin yapılan çalışmalarda farklılık söz konusudur. Yönetim kurullarında bağımsız üyelerin fazla olmasının firma açısından olumsuzluk yaratacağını varsayan çalışmaların yanı sıra olumlu etki yaratacağını varsayan çalışmalar da mevcuttur (Fernandes, 2008; Leung vd., 2014; MacAvoy \& Millstein, 1999; Bhagat \& Black, 1999). Türkiye bağlamında ise özellikle son dönemde gerek Türk Ticaret Kanunu (TTK) gerek kurumsal yönetim ilkeleri çerçevesinde Sermaye Piyasası Kurumu (SPK) bağımsız yönetim kurulu üyeliği ile ilgili çeşitli zorunluluklar getirmiştir. SPK kurumsal yönetim ilkelerine göre, yönetim kurulunda, sayısı ikiden az olmamak üzere, toplamın en az üçte biri bağımsız üyelerden oluşur (SPK, 2012, s. 10). Bu çalışmada ise bağımsız üye sayısı, yönetim kurulu içerisindeki oranı alınarak endekse dâhil edilmiştir.

Yönetim kurulu içerisindeki yabanc1 üye sayısı ile firma performansı arasındaki ilişki ile ilgili literatür incelendiğinde ise farklı sonuçlar elde edildiği görülmektedir. Bu ilişkinin bazı çalışmalarda firma performansı üzerinde pozitif yönde etkili olduğu görülmektedir (Oxelheim \& Randøy, 2003; Choi vd., 2007; Ujunwa, 2012; Shukeri vd., 2012). Bazı çalışmalarda ise bu ilişsinin negatif yönlü olduğu belirtilmektedir (Masulis vd., 2012; Cavaco vd., 2013; Rose, 2007). Türkiye bağlamında ise yönetim kurulunda yabancı üyenin olması Vekalet Teorisine göre yönetim kurulunun etnik çeşitliliğini artıracaktır. Buna bağlı olarak yönetim kurulu bağımsızlığının firma performansını artıracağ 1 düşünülmektedir (Doğan ve Topal, 2016, s. 38). Bu kapsamda çalışmada yabancı üye değişkeni 
yönetim kurulunda yabancı üye yer alıp almadığı dikkate alınarak endekse dâhil edilmiştir.

Bin-Shariman vd., (2015, s. 403)'ne göre, yönetim kurulunda yer alan finansal uzman (Byrd \& Mizruchi 2005), müdür sayısı (Haniffa \& Cooke, 2002) ile yıllık yapılan toplantı sayısı (Saad, 2010) gibi yönetim kurulu karakteristikleri de hem yönetim kurulu kalitesinin belirlenmesinde hem de firmanın finansal başarısı üzerinde etkilidir (Bin-Sariman vd., 2015: 403). Yönetim kurulunda finansal uzmanın varlığının ve müdür sayısının Türkiye bağlamında da bir yönetim kurulu kalite göstergesi olabileceği düşünülmesine rağmen yıllık yönetim kurulu toplantı sayısının bir kalite göstergesi olarak kullanılamayacağ düşünülerek endeks içerisine alınmamıştır. Bunun sebeplerinden bir tanesi olağan üstü durumlarda yapılan toplantı sayılarının sanki olumlu bir göstergeymiş gibi endekste kullanılmasının sonuçlar açısından yanıltıcı olacağıdır. Aynı zamanda Türkiye'de bu verinin sağliklı bir şekilde elde edilebilme sorunu da çalışma sonuçlarını etkilememesi açısından ilgili değişkeni endeks dişı bırakma nedenlerinden bir diğeridir. Bu çerçevede, çalışmada Bin-Sariman vd., (2015) tarafindan geliştirilen yönetim kurulu kalite endeksi Türkiye bağlamına uyarlanarak hazırlanmıştır. Bu kapsamda çalışmada yönetim kurulu büyüklüğü, yönetim kurulu bağımsız üye durumu, yönetim kurulunda finansal uzman varlığı, yönetim kurulunda yer alan müdür sayısı ve yönetim kurulu yabanc1 üye varlığ gibi 5 adet değişken yardımıyla Yönetim Kurulu Kalite Endeksi (BDQ Endeksi) hesaplanmıştır. Söz konusu kalite endeksi içerisine dâhil edilmesi düşünülen fakat literatürde hala fikir birliğine varılamamış iki değişken daha söz konusudur. $\mathrm{Bu}$ değişkenlerden bir tanesi CEO ikiliği bir diğeri ise yönetim kurulundaki kadın üyelerdir. $\mathrm{Bu}$ iki değişkenin varlığının yönetim kurulu kalitesine etki edip edemeyeceği tartışmaya açık olduğu için bu iki değişken de çalışmanın diğer değişkenleri olarak dikkate alınmıştır. Böylece Türkiye bağlamında söz konusu iki değişkenin de firma performansı üzerinde bir etki yaratıp yaratmadığı incelenmiştir.

\section{B. CEO İkiliği}

İkilik, kurumsal yönetimde en tartışmalı konulardan bir tanesidir. Literatür incelendiğinde, yönetim kurulu başkanının aynı zamanda CEO (genel müdür) olmasını ifade eden ikiliğin firma performansı üzerindeki etkilerini açıklayan iki tür teoriden bahsetmek mümkündür. $\mathrm{Bu}$ teorilerden bir tanesi Agency Teori (Vekalet Teorisi), bir diğeri ise Stewardship Teorisi (Temsil Torisi) olarak karşımıza çıkmaktadır. Vekalet Teorisine göre, yönetim kurulu başkanının aynı zamanda genel müdür olması yönetim ve kontrol ayırımı ilkesine zarar vermekte ve firma performansını olumsuz yönde etkilemektedir (Rechner \& Dalton 1991; Fama ve Jensen, 1983). Temsil Teorisine göre ise ikiliğin varlı̆̆ firmanın amaçlarına daha fazla odaklanmasını ve kararlarını hızlı bir şekilde alarak uygulanmasını sağlayacaktır (Donaldson \& Davis, 1991; Moyer vd., 1996). $\mathrm{Bu}$ nedenle ikilik uygulaması firma performansını artırıcı bir unsur olarak görülmektedir. 
Literatürde ise ikiliğin firma performansı üzerindeki etkilerini araştıran çalışmalarda farklı ülkelerde, farklı zamanlarda, farklı sonuçlara ulaşıldı̆̆ 1 görülmektedir (Rechner \& Dalton, 1991; Boyd, 1995; Brickley vd., 1997; Tian \& Lau, 2001; En-Bai vd., 2004; Elitaş vd., 2009; Aygün \& İç; 2010; Lam \& Lee, 2008). $\mathrm{Bu}$ çalışmada ise CEO ikiliğinin BIST 100 endeksinde yer alan sanayi firmalarının finansal performansları üzerinde nasıl bir etki yarattığını incelemek açısından söz konusu değişken analize dâhil edilmiştir.

\section{Yönetim Kurulundaki Kadın Üyeler}

Son zamanlarda, cinsiyet çeşitliliği de yönetim kurulu yapısı kapsamında literatürde fazlaca tartış1lan konulardan bir tanesidir. Literatürde, yönetim kurulu içerisinde yer alan kadın sayısı ile firma performansı arasındaki ilişki hem Vekalet Toerisi hem de Kaynak Bağımlılığı Teorsi'ne göre ele alınmaktadır (Ocak, 2013, s. 108). Bu kapsamda yönetim kurullarında kadın üye bulunmasının firmaların finansal performansları üzerinde olumlu etki yarattığına işaret eden çalışmalar söz konusudur (Francoeur vd., 2008; Erhardt vd., 2003; Carter vd., 2003; Campbell \& Minguez-Vera, 2008; Joecks vd., 2012; Mahadeo vd., 2012; Priya \& Nimalthasan, 2013). Bununla birlikte kadın üye sayısının performans üzerinde olumsuz etkisi olduğunu ya da hiç etkisi olmadığını ileri süren çalışmalar da mevcuttur (Menteş, 2011; Shukeri vd., 2012; Farrell \& Hersch, 2005). Vekalet teorisi açısından kadınlar, karmaşık durumlara yeni bir bakış açısı getirerek strateji geliştirme ve problem çözmede daha doğru bilgisel yanlılık göstermeye yardımcı olabilmektedir (Francoeur vd., 2008, s. 84).

Türkiye'de ise kadın yönetim kurulu üyeleri ile ilgili 2012 yılına kadar her hangi bir düzenleme yapılmamıştır. Fakat 2011 y1lında "Kurumsal Yönetim İlkelerinin Belirlenmesine ve Uygulanmasına İlişkin Tebliğde" yapılan değişiklikle birlikte "yönetim kurulunda en az bir kadın üye bulunur" ilkesi getirmiştir (SPK, 2012, s. 12). Ancak bu ilke bir tavsiye niteliğinde olup zorunluluk taşımamaktadır. Bu kapsamda, tebliğ uyarınca firmaların kadın yönetim kurulu üyelerine yönetim kurullarında daha fazla yer verecekleri beklenmektedir (Karayel, 2014, s. 76). Yönetim kurulu içerisinde kadınların olması hem Vekalet hem de Kaynak Bağımlılı̆̆ Teorisi çerçevesinde yönetim kurullarına yeni bir bakış açısı katacak ve bir çeşitlilik yaratarak kaynaklardaki çeşitliliğin arttırmasını sağlayacaktır. Bunun da firma performansını olumlu yönde etkilemesi beklenmektedir. Bu bağlamda çalışmada yönetim kurulu içerisindeki kadın üye oranının BIST 100 endeksinde yer alan sanayi firmalarının finansal performansları üzerinde nasıl bir etki yarattığını görmek açısından söz konusu değişken analize dâhil edilmiştir.

\section{ARAŞTIRMA METODOLOJISİ}

\section{A. Örneklem ve Veri Toplama Yöntemi}

Bu çalışmanın örneklemini, 2015 yılında Türkiye'de faaliyet gösteren ve Borsa İstanbul 100 endeksinde (BİST 100) yer alan sanayi firmaları oluşturmaktadır. $\mathrm{Bu}$ kapsamda ilgili firma verileri 2009 yllından itibaren paylaşıldığından dolayı 2009-2014 yılları arasında verilerinin tamamına eksiksiz ulaşılan 55 firma incelenmiştir. 
Çalışma kapsamında finansal veriler BIST (www.borsaistanbul.com), Kamuyu Aydınlatma Platformu'na ait (www.kap.gov.tr) veri tabanlarından ve Finnet Programı aracılığı ile elde edilmiştir. Yönetim kurulu yapısına ilişkin veriler ise KAP'ın şirketler yıllığından, firmaların faaliyet raporlarından ve web sayfalarındaki bilgilerinden sağlanmıştır.

\section{B. Araştırmanın Değişkenleri ve Ölçümlenmesi}

Araştırmada üç adet bağımlı değişken ve üç adet de bağımsız değişken söz konusudur. Bağımlı değişken olarak muhasebe esaslı performans göstergeleri olan aktif karlılık (ROA) ve öz sermaye karlılığı (ROE) ile birlikte piyasa esaslı performans göstergesi olan Tobin Q kullanılmıştır. Bu çalışma kapsamında kullanılan değişkenler, kodları ve ölçüm yöntemleri Tablo 1'de özetlenmiştir.

Tablo 1. Araştırma Değişkenleri, Kodları ve Ölçümleri

\begin{tabular}{|c|c|}
\hline Değişkenler (Kodlar) & Ölçümleri \\
\hline \multicolumn{2}{|l|}{ Bağımsız Değişkenler } \\
\hline CEO ikiliği (İKİLİK) & CEO ve yönetim kurulu başkanı aynı kişi ise 1 , farklı kişi ise 0 . \\
\hline Kadın üye oranı (KADIN) & Kadın üye sayıs1 / Yönetim kurulu üye sayısı \\
\hline $\begin{array}{l}\text { Yönetim Kurulu Kalite } \\
\text { Endeksi (BDQ) }\end{array}$ & $\begin{array}{l}\text { Endeksi oluşturan değişkenler } 1 \text { puan üzerinden } \\
\text { değerlendirilmiştir. Tüm değişkenlerin toplamı endeks değerini }\end{array}$ \\
\hline Y.K büyüklüğü & Y.K üye sayısı ortalamadan küçükse 1 puan, büyükse 0 puan \\
\hline Y.K bağımsız üye & Y.K bağımsız üye oranı ortalamadan büyükse 1 , değilse 0 puan \\
\hline Y.K finansal uzmanı & Y.K içerisinde finans uzmanı varsa 1 puan, yoksa 0 puan almıştır. \\
\hline Y.K müdür & Y.K içerisinde müdür varsa 1 puan, yoksa 0 puan almıştır. \\
\hline Y.K yabanc1 üye & Y.K içerisinde yabancı üye varsa 1 puan, yoksa 0 puan almıştır. \\
\hline \multicolumn{2}{|l|}{ Bağımlı Değişkenler } \\
\hline Aktif kârlılık (ROA) & Net kâr / Toplam varlıklar \\
\hline Öz sermaye kârlılı̆̆ 1 ROE) & Net kâr / Öz sermaye \\
\hline Tobin q (Q) & Piyasa Değeri / Defter Değeri \\
\hline \multicolumn{2}{|l|}{ Kontrol Değişkenleri } \\
\hline Firma yaşı (YAŞ) & Gözlem yıl1-İşletmenin kurulduğu yıl \\
\hline Firma büyüklüğü (BÜY) & Firmanın net satışlarının logaritması alınmıştır. \\
\hline
\end{tabular}

Tablo 1'e göre, aktif karlılık (ROA), dönem net karının aktif toplamına oranlanması ile elde edilmiştir. Bu oran firmanın karlılığını göstermektedir. Öz sermaye karlılı̆̆ı (ROE), dönem net karının öz sermayeye oranlanması ile elde edilmiştir. $\mathrm{Bu}$ oran ortakların firmaya yapmış oldukları yatırımın etkinliğini gösterir. Tobin Q değeri ise firmanın piyasa değerinin defter değerine oranlanması ile bulunmuştur. $\mathrm{Bu}$ oran yatırımcıların şirketi nasıl değerlendirdiğine ilişkin bilgi vermektedir. Bağımsız değişken olarak ise yönetim kurulu kalitesi, CEO ikiliği ve kadın üye oranı kullanılmıştır. Yönetim kurulu kalitesi ölçülürken yönetim kurulu büyüklüğü, bağımsız üye oranı, finansal uzman, müdür ve yabancı üye varlığı değişkenleri kullanılmıştır. Diğer bağımsız değişkenlerden CEO ikiliği 
ölçümünde yönetim kurulu başkanı ve CEO'nun aynı kişi olup olmadığına bakılmıştır. Kadın üye değişkeni ise yönetim kurulundaki kadın üye oranı ile hesaplanmıştır. Bunlarla birlikte firma büyüklüğü ve firma yaşı da kontrol değişkenleri olarak dikkate alınmıştır. Firma büyüklüğü ele alınırken literatürde farklı görüşler olmakla birlikte firmanın net satışları dikkate alınmıştır (Rajan \& Zingales. 1995; Demirhan, 2009; Huang \& Song, 2006).

\section{Araştırmanın Hipotez, Model ve Yöntemi}

Tablo 1'de yer alan bağımlı, bağımsız ve kontrol değişkenleri dikkate alınarak Türkiye bağlamında aşağıdaki hipotez ve modeller oluşturulmuştur.

$\boldsymbol{H}_{1 a}:$ YK kalitesi ile ROA arasında pozitif yönlü bir ilişki vardır.

$\boldsymbol{H}_{1 b}$ : CEO ikiliği ile ROA arasında negatif yönlü bir ilişki vardır.

$\boldsymbol{H}_{\boldsymbol{l}}$ : YK kadın oranı ile ROA arasında pozitif yönlü bir ilişki vardır.

$\boldsymbol{H}_{2 a}$ : YK kalitesi ile ROE arasında pozitif yönlü bir ilişki vardır.

$\boldsymbol{H}_{2 b}$ : CEO ikiliği ile ROE arasında negatif yönlü bir ilişki vardır.

$\boldsymbol{H}_{2 c}$ : YK kadın oranı ile ROE arasında pozitif yönlü bir ilişki vardır.

$\boldsymbol{H}_{3 a}:$ YK kalitesi ile Tobin Q arasında pozitif yönlü bir ilişki vardır.

$\boldsymbol{H}_{3 b}$ : CEO ikiliği ile Tobin Q arasında negatif yönlü bir ilişki vardır.

$\boldsymbol{H}_{3 c}$ : YK kadın oranı ile Tobin Q arasında pozitif yönlü bir ilişki vardır.

Çalışmanın amaçlarından birincisi, yönetim kurulu kalitesinin firma performansı üzerindeki etkisini ortaya koymaktır. İkincisi, CEO ikiliği ve firma performansı arasındaki ilişkiyi incelemektir. Üçüncüsü ise yönetim kurulundaki kadın oranı ve firma performansı arasındaki ilişkiyi incelemektir. Bu amaçlar doğrultusunda çalışma kapsamında incelenen 55 firmanın 2009-2014 dönemi yıllık verilerinden faydalanılarak mevcut hipotezler panel veri analizi yöntemi ile test edilmiştir. $\mathrm{Bu}$ yöntem doğrultusunda geliştirilen modeller i birimi, t zamanı göstermek üzere şu şekilde oluşturulmuştur:

Model 1:

$\mathrm{ROA}_{\mathrm{it}}=\beta_{0}+\beta_{1} \mathrm{BDQ}_{\mathrm{it}}+\beta_{2} \dot{\mathrm{IK}} \dot{\mathrm{ILI}} \dot{I}_{\mathrm{it}}+\beta_{3} \mathrm{KADIN}_{\mathrm{it}}+\beta_{4} \mathrm{BÜ} \mathrm{Y}_{\mathrm{it}}+\beta_{5} \mathrm{YASS}_{\mathrm{it}}+\varepsilon_{\mathrm{it}}(1)$

Model 2:

$\mathrm{ROE}_{\mathrm{it}}=\beta_{0}+\beta_{1} \mathrm{BDQ} \mathrm{it}_{\mathrm{it}}+\beta_{2} \dot{I}_{\mathrm{II}} \dot{\mathrm{I}} \dot{\mathrm{I}} \mathrm{K}_{\mathrm{it}}+\beta_{3} \mathrm{KADIN}_{\mathrm{it}}+\beta_{4} \mathrm{BÜ} \mathrm{Y}_{\mathrm{it}}+\beta_{5} \mathrm{YAS}_{\mathrm{it}}+\varepsilon_{\mathrm{it}}(2)$

Model 3:

$\mathrm{Q}_{\mathrm{it}}=\beta_{0}+\beta_{1} \mathrm{BDQ}_{\mathrm{it}}+\beta_{2} \dot{\mathrm{I}} \mathrm{KI} \dot{\mathrm{I}} \mathrm{K}_{\mathrm{it}}+\beta_{3} \mathrm{KADIN}_{\mathrm{it}}+\beta_{4} \mathrm{BÜK} \mathrm{K}_{\mathrm{it}}+\beta_{5} \mathrm{YAS}_{\mathrm{it}}+\varepsilon_{\mathrm{it}}(3)$ 


\section{ARAŞTIRMANIN BULGULARI}

\section{A. Tanımlayıcı İstatistikler}

Çalışmada kullanılan değişkenlerin tamamına ilişkin tanımlayıcı istatistikler Tablo 2'de sunulmuştur.

Tablo 2. Tanımlayıcı İstatistikler

\begin{tabular}{lccccc}
\hline \hline Değişkenler & $\mathbf{N}$ & Ortalama & S. Sapma & Minimum & Maksimum \\
\hline \hline ROA & 330 & 0.0665 & 0.0860 & -0.1479 & -0.5726 \\
\hline ROE & 330 & 0.1290 & 0.1773 & -0.5505 & -0.7647 \\
\hline Q & 325 & 2.2361 & 2.2371 & 0.24 & 16.64 \\
\hline BDQ & 330 & 1.9151 & 0.9669 & 0 & 5 \\
\hline İKİLIK & 330 & 0.0363 & 0.1874 & 0 & 1 \\
\hline KADIN & 330 & 0.1085 & 0.1227 & 0 & 0.5 \\
\hline YAŞ & 330 & 37.7 & 16.917 & 1 & 78 \\
\hline BÜY & $\mathbf{3 3 0}$ & $\mathbf{3 4 4 8 5 5 8 8 8 6}$ & $\mathbf{5 8 4 9 1 5 1 7 0 4}$ & $\mathbf{6 9 1 3 4 7 4}$ & $\mathbf{4 2 4 3 6 9 0 8 0 0 0}$ \\
\hline \hline
\end{tabular}

Tabloda değişkenlerin gözlem sayısı, ortalaması, standart sapmas1, minimum ve maksimum değerleri yer almaktadır. Buna göre çalışmada 330 gözlemden yararlanılmıştır. $\mathrm{Bu}$ doğrultuda bağımsız değişkenlerden BDQ endeksinin ilgili dönemde ortalaması 1.91, minimum değeri 0 ve maksimum değeri 5 olarak gerçekleşmiştir. Kadın oranının ortalaması 0.10 minimum değeri 0 , maksimum değeri ise 0.5 olurken ikilik değişkeninin ortalaması 0.03 , minimum değeri 0 , maksimum değeri ise 1 'dir.

\section{B. Korelasyon Analizleri}

Çalışmada kullanılan değişkenler arasındaki korelasyon ilişkileri ise Tablo 3'te görülebilmektedir.

Tablo 3. Korelasyon Matrisi

\begin{tabular}{|c|c|c|c|c|c|c|c|c|}
\hline & 1 & 2 & 3 & $\overline{4}$ & 5 & $\overline{6}$ & $\overline{77}$ & $\overline{88}$ \\
\hline$R O A$ & 1 & & & & & & & \\
\hline ROE & $.8589^{* * * *}$ & 1 & & & & & & \\
\hline$Q$ & $.3149^{*}$ & $.4152^{* * * *}$ & 1 & & & & & \\
\hline$B D Q$ & .0066 & .0315 & .0884 & 1 & & & & \\
\hline ÍKIILIK & -.0874 & -.0464 & .0752 & $.1511^{* * * *}$ & 1 & & & \\
\hline KADIN & $.0912^{*}$ & -.0606 & $-.1665^{* * * *}$ & $-.1331^{* * *}$ & .0176 & 1 & & \\
\hline$B \ddot{U} Y$ & $.0992^{*}$ & $.2460^{* * * *}$ & $-.2461^{* * * *}$ & .0375 & -.0715 & $-.2087^{* * * *}$ & 1 & \\
\hline $\boldsymbol{Y A S S}$ & -.0520 & -.0376 & $.1480^{* * * *}$ & .0148 & -.0372 & -.0344 & -.0236 & 1 \\
\hline
\end{tabular}

Not: $* \mathrm{p}<0.10 ; * \mathrm{p}<0.05 ; * * * \mathrm{p}<0.01$

Korelasyon analizi, değişkenler arasında ilişki olup olmadığını, varsa bu ilişkinin ne yönde olduğunu tespit edebilmek için gerçekleştirilmektedir. 
Korelasyon katsayısı -1 ile +1 arasında değerler almaktadır. Eğer $r=0.00-0.25$ ise ilişki çok zayıf, $r=0.26-0.49$ ise ilişki zayıf, $r=0.50-0.69$ ise ilişki orta, $r=0.70$ 0.89 ise ilişki yüksek, $r=0.90-1.00$ ise ilişki çok yüksek kabul edilmektedir (Kalaycı, 2010: s. 116). Korelasyon analizinde bağımsız değişkenler arasında meydana gelebilecek olan kuvvetli ilişkiler çoklu doğrusal bağlantı olarak ifade edilmektedir. Korelasyonla ilgili bulgulara genel olarak bakıldığında araştırmada herhangi bir çoklu bağlantı problemine rastlanmamıştır. Araştırma modelinde yer alan bağımsız değişkenlerin arasında yüksek düzeyde ilişkiler tespit edilmemiştir. Bu kapsamda söz konusu ilişkilerden hiçbiri çoklu bağlantı problemi için alt sınır olarak kabul edilen (r) 0.800 ve üzerinde gerçekleşmemiştir (Gujarati, 2004: s. 359). Buna göre değişkenler arasındaki en yüksek korelasyon ilişkisi muhasebe esaslı performans göstergeleri olan ROA ile ROE arasında gerçekleşmiştir (0.85).

\section{Panel Veri Analizi}

Çalışmada, oluşturulan üç model çerçevesinde panel veri analizi kullanılmıştır. Modellerde sabit etkiler ve tesadüfi etkiler tahmincilerinden hangisinin kullanılacağına karar vermek için Hausman Testine başvurulmuştur. Buna göre Model 1 ve Model 2'de olasılık değeri 0.05' in altında olduğundan sabit etkiler modeli kullanılmıştır. Model 3'te ise olasılık değeri 0.05'in üzerinde olduğundan tesadüfi (rassal) etkiler modeli kullanılmıştır. Model 1 ve 2'nin analiz sonuçları Tablo 4'te, Model 3'ün analiz sonuçları ise Tablo 5'te sunulmuştur. Ayrıca Hausman Testi sonuçları da her iki tablonun son iki satırında görülebilmektedir.

Tablo 4. Model 1 ve Model 2'ye İlişkin Analiz Sonuçları

\begin{tabular}{|c|c|c|c|c|c|c|}
\hline & \multicolumn{3}{|c|}{$\begin{array}{c}\text { MODEL } 1 \text { (ROA) } \\
\text { (Sabit Etkiler) }\end{array}$} & \multicolumn{3}{|c|}{$\begin{array}{c}\text { MODEL 2 (ROE) } \\
\text { (Sabit Etkiler) }\end{array}$} \\
\hline & $\begin{array}{l}\text { Bek. } \\
\text { İsaret }\end{array}$ & Katsayı & t-stat & $\begin{array}{c}\text { Bek. } \\
\text { İsaret }\end{array}$ & Katsayı & t-stat \\
\hline BDQ & + & $0.0212^{* * * *}$ & 4.15 & + & $0.0386^{* * *}$ & 3.35 \\
\hline ÍKİLIK & - & $-0.0532^{* *}$ & -2.12 & - & -0.0129 & -0.24 \\
\hline KADIN & + & $0.1265^{* *}$ & 2.27 & + & $0.2832^{* * *}$ & 2.31 \\
\hline YASS & - & $-0.0123^{* * *}$ & -3.60 & - & $-0.0214^{* * *}$ & -2.94 \\
\hline BÜY & + & 0.0221 & 1.19 & + & 0.0513 & 1.25 \\
\hline SABÍT & & 0.0281 & 0.11 & & -0.2264 & -0.37 \\
\hline 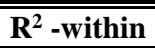 & 0.15 & & & 0.10 & & \\
\hline F-stat & $7.82^{* * * *}$ & & & $5.01^{* * * *}$ & & \\
\hline 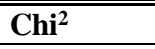 & 19.85 & & & 15.02 & & \\
\hline Prob>chi2 & $(0.0013)$ & & & $(0.0103)$ & & \\
\hline
\end{tabular}

Not: ${ }^{*} \mathrm{p}<0.10 ;{ }^{*} \mathrm{p}<0.05 ; * * * \mathrm{p}<0.01$. Parantez içerisindeki prob. değerleri Hausman test sonuçlarıdır.

Tablo 4'e göre, sabit etkiler tahmincisiyle çözülen ilk iki modelin (Model 1 ve Model 2) bir bütün olarak anlamlı olduğu sonucuna ulaşılmıştır. Bununla birlikte Model 1'de ROA üzerinde bağımsız değişkenlerden BDQ ve kadın oranının pozitif, ikiliğin ise negatif ve anlamlı etkileri olduğu sonucuna ulaşılmıştır. ROE üzerinde ise yine bağımlı değişkenlerden BDQ ve kadın oranı 
pozitif ve anlamlı birer etkiye sahiptir. Öte yandan, kontrol değişkenlerinden firma büyüklüğünün her iki modelde de herhangi bir anlamlı etkisinin olmadığı, buna karşın firma yaşının her iki modelde de negatif ve anlamlı bir etkisinin olduğu tespit edilmiştir.

Tablo 5. Model 3'e İlişkin Analiz Sonuçları

\begin{tabular}{|l|ccc|}
\hline \hline & \multicolumn{3}{|c|}{ MODEL 3 (TOBIN Q) } \\
\hline \hline & $\begin{array}{c}\text { Beklenen } \\
\text { İşaret }\end{array}$ & Katsayı & t-stat \\
\hline \hline BDQ & + & 0.0633 & 0.76 \\
\hline İKiLIK & - & -0.1735 & -0.46 \\
\hline KADIN & + & $1.8101^{* *}$ & 2.05 \\
\hline YAŞ & - & $-0.0302^{* *}$ & -2.13 \\
\hline BÜY & + & $0.3985^{* * *}$ & 3.28 \\
\hline SABİT & & $-5.1888^{* *}$ & -2.08 \\
\hline \hline $\mathbf{R}^{2}$-within & 0.03 & & \\
\hline Wald chi $^{2}$ & $16.98^{* * *}$ & & \\
\hline \hline Chi $^{2}$ & 4.73 & & \\
\hline Prob $>$ chi2 $^{*}$ & $\mathbf{( 0 . 4 5 0 3 )}$ & & \\
\hline \hline
\end{tabular}

Not: $* \mathrm{p}<0.10 ; * * \mathrm{p}<0.05 ; * * * \mathrm{p}<0.01$. Parantez içerisindeki prob. değerleri Hausman test sonuçlarıdır.

Tablo 5'e göre ise tesadüfi etkiler tahmincisiyle çözülen Model 3'ün bir bütün olarak anlamlı olduğu sonucuna ulaşılmıştır. Bununla birlikte Model 3'te Tobin Q üzerinde bağımsız değişkenlerden sadece kadın oranının pozitif ve anlamlı bir etkisi olduğu sonucuna ulaşılmıştır. Model 3'te de diğer modellerde olduğu gibi firma yaşının negatif ve anlamlı bir etkisinin olduğu tespit edilmiştir. Ayrıca firma büyüklügünün de pozitif ve anlamlı etkisi görülmüştür.

Elde edilen sonuçlar doğrultusunda, Şekil 1'de bağımsız değişkenlerin firma performans ölçütleri üzerindeki anlamlı etkileri, oluşturulan hipotezler çerçevesinde daha açık bir biçimde görülebilmektedir. Bu doğrultuda, çalışma kapsamında Model 1 için oluşturan $\mathrm{H}_{1 \mathrm{a}}, \mathrm{H}_{1 \mathrm{~b}}$ ve $\mathrm{H}_{1 \mathrm{c}}$; Model 2 için oluşturulan $\mathrm{H}_{2 \mathrm{a}}$ ve $\mathrm{H}_{2 \mathrm{c}}$ hipotezleri ile Model 3 için oluşturulan $\mathrm{H}_{3 \mathrm{c}}$ hipotezleri kabul edilmiştir. Başka bir ifadeyle Yönetim Kurulu Kalitesi (BDQ), ikilik ve kadın oranı ROA; Yönetim Kurulu Kalitesi (BDQ) ve kadın oranı ROE; kadın oranı ise Tobin Q üzerinde anlamlı etkilere sahiptir. Söz konusu etkiler Şekil 1'de görülebilmektedir. 
Şekil 1. Firma Performansı Üzerinde Etkili Olan Bağımsız Değişkenler

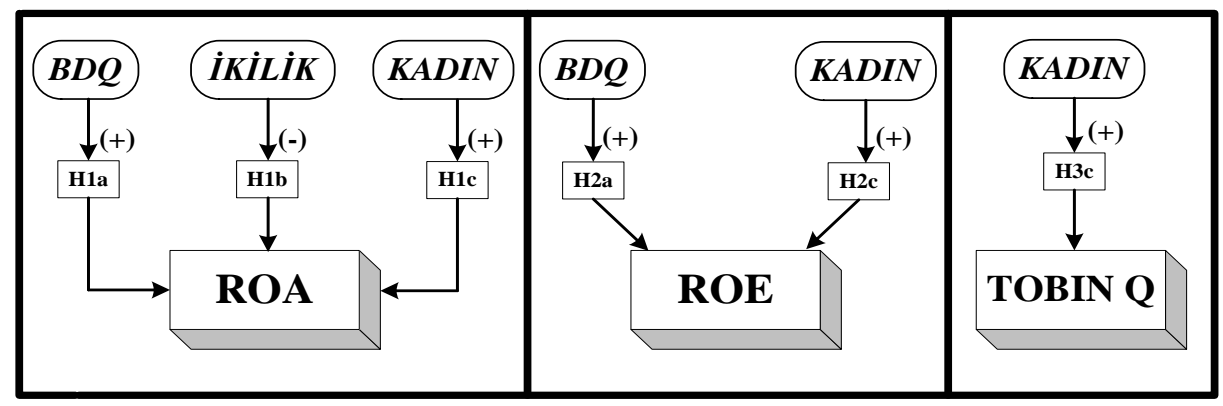

SONUÇ

Yönetim kurullarının firmalardaki görev ve sorumlulukları ülkeden ülkeye farkl1lık gösterebilir. Fakat üstlendikleri görev ve sorumluluklar itibari ile tüm ülkelerde finansal performans üzerinde bir etkiye sahip olduklarını söylemek mümkündür. Literatürde yönetim kurulu yapısı ile firma performansı arasındaki ilişkiye yönelik birçok çalışma mevcuttur. Söz konusu çalışmalarda genellikle yönetim kurulu büyüklüğü, bağımsız ve yabancı üye gibi değişkenler çalışılmıştır. $\mathrm{Bu}$ çalışmada ise yönetim kurulu yapısı ile ilgili toplulaştırılmış bir kalite endeksi oluşturulmuştur. Bu kapsamda araştırmada yönetim kurulu kalitesinin firma performansı üzerindeki etkisi incelenmiştir. Bununla birlikte CEO ikiliği ve yönetim kurulundaki kadın üye oranının firma performansı üzerindeki etkisi de araştırılmıştır.

$\mathrm{Bu}$ amaç kapsamında gerçekleştirilen çalışmada yönetim kurulu kalitesinin, CEO ikiliğinin ve yönetim kurulundaki kadın üye oranının firma performansı göstergeleri üzerinde etkisi olduğunu gösteren bulgulara rastlanmıştır. $\mathrm{Bu}$ bağlamda çalışmada yönetim kurulu kalitesinin (BDQ) artmasının firmanın aktif karlılığı ve öz sermaye karlılığ1 üzerinde olumlu ve anlamlı bir etkiye sahip olduğu dikkat çekmektedir. Bunun anlamı, yönetim kurulu mevcudu fazla olmayan, bağımsız üye oranı fazla olan, yabancı üye, finansal uzman ve müdür bulunan yönetim kurullarına sahip firmalardaki muhasebe esaslı finansal göstergelerin (ROA ve ROE), diğerlerine göre daha yüksek olduğudur.

Genel müdür (CEO) ve yönetim kurulu başkanının aynı kişi olması ise söz konusu finansal performans göstergelerinden yalnızca aktif karlılık (ROA) üzerinde olumsuz ve anlamlı bir etkiye sebep olmaktadır. Bu sonuç, yönetim kurulu başkanı ve genel müdürün (CEO) aynı kişi olduğu firmalarda genel müdürün denetlenmesinin zor olduğunu ve genel müdürün yönetim kurulunu yönlendirerek fïma performansını olumsuz yönde etkileyeceğini ileri süren Vekalet Teorisi ile tutarl11ık göstermektedir.

Yönetim kurulu içerisinde yer alan kadın oranı ise yönetim kurulu çeşitliliği ve buna bağlı olarak yönetim kurulunun daha bağımsız olmasını 
sağlayarak performansı olumlu etkileyen bir unsur olarak görülmektedir. Çalışmada da kadın oranının muhasebe esaslı performans göstergeleri olan ROA ve ROE ile birlikte piyasa esaslı performans göstergesi olan Tobin Q üzerinde olumlu ve anlamlı bir etkiye sahip olduğu görülmektedir. Bu sonuç ise yönetim kurullarında kadın bulunduran firmaların farklılık yarattığını göstermesi açısından önemlidir. Bu durum Türkiye'de yönetim kurullarında kadın bulundurulmasına ilişkin alınan Sermaye Piyasası Kurulu (SPK) kararının yerinde bir karar olduğunu, fakat kararın sadece tavsiye niteliği taşıması açısından ise eksik olduğunu düşündürmektedir.

Yönetim kurulu kalite endeksi (BDQ) hazırlanarak literatüre katkıda bulunmayı hedefleyen bu çalışma sonuçların genelleştirilmesi adına BIST'te yer alan tüm imalat işletmelerini ele alarak tekrarlanabilir. Ayrıca firma verilerine 2009 yılından itibaren ulaşıldığından dolayı daha ileri zamanlarda daha geniş bir zaman aralığı ele alınarak çalışmaya katkıda bulunulabilir. Ayrıca son yıllarda kurumsal yönetim uygulamalarının finansal performans üzerindeki etkisini inceleyen çalışmalarda kullanılan Z Altman skoru bağımlı değişken olarak ele alınarak çalışma geliştirilebilir.

\section{KAYNAKÇA}

Abdullah, S. (2004). Board Composition, CEO Duality and Performance among Malaysian Listed Companies. Corporate Governance, 4, 47-61.

Arosa, B., Iturralde, T., \& Maseda, A. (2010). Outsiders On The Board Of Directors and Firm Performance: Evidence from Spanish Non-Listed Family Firms. Journal of Family Business Strategy, 1(4): 236-245.

Aygün, M., \& İç, S. (2010). Genel Müdürün Aynı Zamanda Yönetim Kurulu Üyesi Olması Firma Performansinı Etkiler Mi?. Muhasebe ve Finansman Dergisi, 47, 192-201.

Aygün, M., İç, S., \& Sayın, C. (2011). Yönetim Kurulu Büyüklügünü Belirleyen Faktörler ve Yönetim Kurulu Büyüklügü ile Firma Performansı Arasındaki İlişki: Türk Sermaye Piyasası Üzerine Bir İnceleme. Gaziantep Üniversitesi Sosyal Bilimler Dergisi,10(1), 77 92.

Bennedsen, M., Kongsted, H.C., \& Nielsen, K.M. (2008). The Causal Effect of Board Size in The Performance of Small and Medium-Sized Firms. Journal of Banking \& Finance, 32(6), 1098-1109.

Bhagat, S., \& Black, B.S. (1999). The Uncertain Relationship between Board Composition and Firm Performance. Business Lawyer, 54, 921-963.

Bin-Sariman, A.S., Ali, A., \& Nor, M.N.M. (2015). Board of Directors' Quality and Firms' Debt Financing: The Moderating Effect of Insider Ownership-Evidence from Omani Firms. Applied Economics, 48(5), 402-410.

Bonn, I., Yoshikawa, T., \& Phan, P.H. (2004). Effects of Board Structure on Firm Performance: A Comparison between Japan and Australia. Asian Business \& Management, 3, 105-125.

Boyd, B. (1995). CEO Duality and Firm Performance: A Contingency Model. Strategic Management Journal, 16, 301-312.

Bozec, R. (2005). Boards of Directors, Market Discipline and Firm Performance. Journal of Business Finance \& Accounting, 32(9), 1921-1960.

Brickley, J., Coles J., \& Jarrell G. (1997). Leadership Structure: Separating The CEO and Chairman of the Board. Journal of Corporate Finance, 4, 189-220. 
Byrd, D. T., \& Mizruchi M.S. (2005). Bankers on the Board and the Debt Ratio of Firms. Journal of Corporate Finance, 11, 129-173.

Campbell, K., \& Minguez-Vera, A. (2008). Gender Diversity in The Boardroom and Firm Financial Performance. Journal of Business Ethics, 83(3), 435-451.

Carter, D.A., Simkins, B.J., \& Simpson, W.G. (2003). Corporate Governance, Board Diversity and Firm Value. The Financial Review, 38, 33-53.

Cavaco, S., Challe, E., Crifo, P., Reberioux, A., \& Roudaut, G. (2013). Board Independence and Operating Performance: Analysis On (French) Company and Individual Data. Ecole Polytechnique Centre National De La Recherche Scientifique, 1-29.

Cheng, S., Evans, J. H., \& Nagarajan, N. J. (2008). Board Size and Firm Performance: The Moderating Effects of the Market for Corporate Control. Review of Quantitative Finance and Accounting, 31, 121-145.

Choi, J.J., Park, S.W., \& Yoo, S.S. (2007). The Value of Outside Directors: Evidence from Corporate Governance Reform in Korea. Journal of Financial and Quantitative Analysis, 42(4), 941- 962.

Conyon, M., \& Peck, S. (1998). Board Size and Corporate Performance: Evidence from European Countries. European Journal of Finance, 4, 291-304.

Demirhan, D. (2009). Sermaye Yapısını Etkileyen Firmaya Özgü Faktörlerin Analizi: İMKB Hizmet Firmaları Üzerine Bir Uygulama. Ege Academic Review, 9(2), 677-697.

Doğan, M., \& Topal, Y. (2016). Yönetim Kurulundaki Yabancı Üye Sayısının ve Yabancı Sahipliğinin Finansal Performans Üzerindeki Etkisi. Ege Academic Review, 16(1), 31-48.

Donaldson, L., \& Davis, J.H. (1991). Stewardship Theory or Agency Theory: CEO Governance and Shareholder Returns. Australian Journal of Management, 16(1), 49-64.

Elitaş, C., Ağca, V., \& Aydemir, O. (2009). Yönetim Kurulu Yapısı, İşleyişi ve Performans İlişsisi: Ege Bölgesi Örneği. Muhasebe ve Finansman Dergisi, (42), 103-116.

Elsayed, K. (2011). Board Size and Corporate Performance: The Missing Role of Board Leadership Structure. Journal of Management \& Governance, 15(3), 415- 446.

En-Bai, C., Liu, Q., Lu, J., Song, F., \& Zhang, J. (2004). Corporate Governance and Market Valuation in China. Journal of Comparative Economics, 32, 599-616.

Erhardt, N.L., Werbel, J.D., \& Shrader, C.B. (2003). Board of Directors Diversity and Firm Financial Performance. Journal of Corporate Governance: An International Review, 11(2), 102-111.

Fama, E., \& M. Jensen, (1983). Separation of Ownership and Control. Journal of Law and Economics, 26, 301-325.

Farrell, K.A., \& Hersch, P. L. (2005). Additions to Corporate Boards: The Effect of Gender. Journal of Corporate Finance, 11(1), 85-106.

Fernandes, N., (2008). EC: Board Compensation And Firm Performance: The Role of Independent Board Members. Journal of Multinational Financial Management, 18, 30-44.

Francoeur, C., Labelle, R., \& Sinclair-Desgagne, B. (2008). Gender Diversity in Corporate Governance And Top Management. Journal of Business Ethics, 81(1), 83-95.

Gökçen, Z., Sözüer, A., \& Arslantaş, C.C. (2012). Yönetim Kurulu Özellikleri ve Şirket Performansları: İMKB Kurumsal Yönetim ve İMKB 50 Endekslerindeki İşletmelerin Karşılaştırılması. İstanbul Üniversitesi İşletme İktisadı Enstitüsü Dergisi, (72), 77-89.

Gujarati, D. (2004). Basic Econometrics (4. Baskl). New York: McGraw-Hill.

Haniffa, R.M., \& Cooke, T.E. (2002). Culture, Corporate Governance and Disclosure in Malaysian Corporations. Abacus, 38(3), 317-349.

Hermalin, B.E., \& Weisbach, M.W. (1991). The Effects of Board Composition and Direct Incentives on Firm Value. Financial Management, 20, 101-112.

Huang, G., \& Song, F.M. (2006). The Determinants of Capital Structure: Evidence From China. China Economic Review, 17, 14-36. 
Hussain, S.H., \& Mallin, C. (2002). Corporate Governance in Bahrain. Corporate Governance, 10(3), 197-210.

Joecks, J., Pull, K., \& Vetter, K. (2012). Gender Diversity in the Boardroom and Firm Performance: What Exactly Constitutes a Critical Mass?. Journal of Business Ethics, 118(1), 61-72.

Kalaycı, Ş. (Ed.) (2010). SPSS Uygulamalı Çok Değişkenli İstatistik Teknikleri. Ankara: Asil.

Karayel, M., \& Doğan, M. (2014). Yönetim Kurulunda Cinsiyet Çeşitliliği ve Finansal Performans İlişkisi: BIST 100 Şirketlerinde Bir Araştırma. Süleyman Demirel Üniversitesi İktisadi ve İdari Bilimler Fakültesi Dergisi, 19(2), 75-88.

Kyereboah-Coleman, A., \& Biepke, N. (2006). The Link between Corporate Governance and Performance of The Non-Traditional Export Sector: Evidence from Ghana. Corporate Governance, 6(5), 609-623.

Lam, T.Y., \& Lee, S.K. (2008). CEO Duality And Firm Performance: Evidence from Hong Kong. Corporate Governance, 8(3), 299-316.

Larmou, S., \& Vafeas, N., (2009). The Relation between Board Size and Firm Performance in Firms With A History of Poor Operating Performance. Journal of Management Governance, 14(1), 61-85.

Leung, S., Richardson, G., \& Jagg1, B. (2014). Corporate Board and Board Committee Independence, Firm Performance and Family Ownership Concentration: An Analysis Based on Hong Kong Firms. Journal of Contemporary Accounting \& Economics, 10, 16-31.

MacAvoy, P.W., \& Millstein, I.M. (1999). The Active Board of Directors and Its Effect on The Value of The Large Publicly Traded Corporation. Journal of Applied Corporate Finance, 11, 8-20.

Mahadeo, J.D. Soobaroyen, T., \& Hanuman, V.O. (2012). Board Composition and Financial Performance: Uncovering the Effects of Diversity in an Emerging Economy. Journal of Business Ethics, 105, 375-388.

Mak, Y.T., \& Yuanto, K., (2001). Size Really Matters: Further Evidence on The Negative Relationship between Board Size and Firm Value. Pacific-Basin Finance Journal, 13, 301 318.

Masulis, R. W., Wang, C., \& Xie, F. (2012). Globalizing the Boardroom-The Effects of Foreign Directors on Corporate Governance and Firm Performance. Journal of Accounting and Economics, 53(3), 527-554.

Menteş, S.S. (2011). Gender Diversity at the Board and Financial Performance: A Study on ISE (Istanbul Stock Exchange). Middle Eastern Finance and Economics, 14, 6-15.

Moyer, C., Rao, R., \& Baliga, R. (1996). CEO Duality and Firm Performance: hat's the Fuss? Strategic Management Journal, 17, 41-53.

Ocak, M. (2013), Yönetim Kurulu ve Üst Yönetimde Yer Alan Kadınların Finansal Performansa Etkisi: Türkiye'ye İlişkin Bulgular. Muhasebe ve Finansman Dergisi, 60, 107-126.

O'Connell, V., \& Cramer, N. (2010). The Relationship Between Firm Performance and Board Characteristics in Ireland. Journal of European Management Journal, 28(5), 387-399.

Oxelheim, L., \& Randøy, T. (2003). The Impact of Foreign Board Membership on Firm Value. Journal of Banking \& Finance, 27, 2369-2392.

Perry, T., \& Shivdasani, A. (2005). Do Boards Affect Performance? Evidence from Corporate Restructuring. The Journal of Business, 78(4), 1403-1432.

Priya, K., \& Nimalthasan, B. (2013). Board of Directors' Characteristics and Financial Performance: A Case Study of Selected Hotels and Restaurants in Sri Lanka. Journal of Accounting, Auditing, Economics and Finance, 1(2), 18-25.

Rajan, R.G., \& Zingales, L. (1995). What Do We Know about Capital Structure? Some Evidence from International Data. The Journal of Finance, 50, 1421-1460.

Rechner, P.L., \& Dalton, D.R. (1991). CEO Duality and Organisational Performance: A Longitudinal Analysis. Strategic Management Journal, 12, 155-160. 
Rose, C. (2007). Does Female Board Representation Influence Firm Performance? The Danish Evidence. Journal of Corporate Governance: An International Review, 15, 404-413.

Saad, N. M. (2010). Corporate Governance Compliance and the Effects to Capital Structure in Malaysia. International Journal of Economics and Finance, 2, 105-114.

Selekler-Gökşen, N., \& Karataş, A. (2008). Board Structure and Performance in an Emerging Economy: Turkey. International Business Governance and Ethics, 4(2), 132-147.

Sermaye Piyasası Kurumu (SPK). (2012). Kurumsal Yönetim İlkelerinin Belirlenmesine ve Uygulanmasına İlişkin Tebliğ, http://www.spk.gov.tr

Shakir, R. (2008). Board Size, Board Composition and Property Firm Performance. Pacific Rim Property Research Journal, 14(1), 1-16.

Shukeri, S.N., Shin, O.W., \& Shaari, M.S. (2012). Does Board of Director's Characteristics Affect Firm Performance? Evidence From Malaysian Public Listed Companies. International Business Research, 5(9), 120-127.

Staikouras, P.K., Staikouras, C., \& Agoraki, M.E. (2007). The Effect of Board Size and Composition on European Bank Performance. European Journal of Law and Economics, 23, $1-27$.

Taghizadeh, M., \& Saremi, S. (2013). Board of Directors and Firms Performance: Evidence from Malaysian Public Listed Firm. International Proceedings of Economics Development and Research, 59(37), 178-182.

Tian, J. J., \& Lau, C.M. (2001). Board Composition, Leadership Structure, and Performance in Chinese Shareholding Companies. Asia Pacific Journal of Management, 18, $245-263$.

Ujunwa, A. (2012). Board Characteristics and Financial Performance of Nigerian Quoted Firms. Corporate Governance, 12(5), 656-674.

Ülgen, H., \& Mirze, K. (2013). İşletmelerde Stratejik Yönetim. İstanbul, Türkiye: Bet Yayınevi.

Wan, D., \& Ong, C.H. (2005). Board Structure, Process and Performance: Evidence from PublicListed Companies in Singapore. Corporate Governance, 13, 277-290.

Yermack, D. (1996). Higher Market Valuation of Companies With A Small Board of Directors. Journal of Financial Economics, 40, 185-211.

https:// HYPERLINK "http://www.borsaistanbul.com" www.borsaistanbul.com

https://www.kap.org.tr/tr/bist-sirketler

\section{SUMMARY}

In firms, the Board of Directors manages the firm on behalf of shareholders. There are some important tasks and responsibilities of the Board of Directors. The most important task of them is to ensure the sustainability of the firm by determining the policies and strategies. Therefore, the structure and the quality of the Board of Directors is an important factor affecting the firm's performance. In the literature, there are studies about the effects of the structure of the Board of Directors on firm's performance. However, these studies tackled the issues such as the size of the Board of Directors, the independent members in the board, CEO duality, female members in the board, foreign members in the board separately. In this study, the Board of Directors Quality Index was developed. This index is formed by adapting the Board of Directors Quality Index (BDQ) developed by Bin-Sariman et al. (2015) to the context of Turkey. The index included the variables of the size of the Board of Directors, the ratio of independent members in the board, the presence of foreign members, financial 
analysts and directors in the board. In this context, the impact of the quality of the Board of Directors on firm's performance is examined. Additionally; the effects of CEO duality and ratio of female members on the performance of the firm, which has been frequently discussed in the literature, were also studied.

In this context, the aim of the study is to examine the effects of the quality of the Board of Directors, CEO duality and the proportion of female members in the board, on the firm's performance. Within the framework of this aim, 55 firms among the BIST-100 industrial firms in 2015, whose data have been fully accessed have been examined between the years 2008 and 2014. For the analysis of the data, panel data analysis was used and STATA software was utilized. In the scope of the study, Tobin Q was used together with Return on Assets and Return on Equity as performance criteria. The quality of the Board of Directors, CEO duality and the ratio of female members in the board were the independent variables of the study. In addition, the size and the age of the firm, which are thought to have an effect on the firm's performance, are control variables.

According to the results of the research, the findings that show the effect of the quality of the Board of Directors, CEO duality and the ratio of female members in the board, on the performance indicators of the firm, were determined. In this context, the increase in the Board of Directors Quality (BDQ) has a positive and significant effect on the Return on Assets and Return on Equity ratios of the firm. When the general manager (CEO) and the chairman of the Board of Directors are the same person, it has a significant and negative effect only on the Return on Assets (ROA), among the financial performance indicators. This result is consistent with the Theory of Power of Attorney which asserts the difficulty of supervising the general manager in the case of a CEO duality in the firms and that his leading of the Board of Directors influencing the firm performance negatively. The ratio of female members in the board seems to have a significant and positive effect on ROA and ROE, which are accounting-based performance indicators, and on Tobin Q, a market-based performance indicator. This result shows that the firms that have females in the the Board of Directors make a difference. 